\title{
O feminicídio como expressão de poder nas relações de gênero
}

\author{
The feminicide as an expression of power in the relations of \\ between man and woman
}

\author{
Hélio Luiz Fonseca Moreira ${ }^{1}$ \\ Iriscelia Acácio Moreira ${ }^{2}$
}

\begin{abstract}
RESUMO
O estudo teve como principal objetivo, abordar o feminicídio como expressão de poder nas relações de gênero, em um contexto social atravessado pelos elevados índices de violência contra à mulher, cuja expressão mais brutal se materializa na banalização do feminicídio. Tratase de uma pesquisa qualitativa, em matiz transdisciplinar, particularmente, o jurídico e o sociológico, fundada em diversas fontes de evidência, cujas principais foram a pesquisa bibliográfica, e o levantamento de dados correlatos à violência contra à a mulher. A violência e a distribuição desigual do poder na relação entre gêneros serão analisadas com base nas contribuições teóricas elaboradas por Bourdieu (1989, 2003). O estudo evidenciou que, no Brasil, os altos índices de violência, a criminalização secundária e a degradação identitária são fatores que geram insegurança e indignidade às mulheres.
\end{abstract}

PALAVRAS-CHAVE: Violência. Mulher. Feminicídio.

\begin{abstract}
The main objective of the research was to analyze feminicide as an expression of power in gender relations, in a social context with high levels of violence against women, whose most brutal expression materializes in the trivialization of femicide. It is a qualitative research, in a transdisciplinary hue, particularly legal and sociological, founded on several sources of evidence, the main ones being bibliographic research, and the survey of data related to violence against women. Violence and the unequal distribution of power in the relationship between genders will be analyzed based on the theoretical contributions elaborated by Bourdieu (1989, 2003). The study showed that, in Brazil, high rates of violence, secondary criminalization and identity degradation are factors that generate insecurity and indignity for women.
\end{abstract}

KEYWORDS: Violence. Woman. Femicide.

\footnotetext{
${ }^{1}$ Professor de Direito Penal do Instituto de Ciências Jurídicas/UFPA. Pós-doutor em Psicologia Social pelo PPGP da Universidade Federal do Pará (UFPA, 2018/2020), doutor em Ciências Sociais (UFPA, 2007), mestre em Sociologia (UFPA, 2002), Especialista em Educação e Problemas Regionais (UFPA,1993), bacharel em Direito (UFPA, 1999), bacharel em Ciências Sociais (UFPA, 1990). E-mail: helfm@yahoo.com.br

${ }^{2}$ Bacharelanda em Direito da Universidade da Amazônia (UNAMA). E-mail: irisamodireito@gamil.com
} 


\section{Introdução}

O presente trabalho teve como principal objetivo, abordar o feminicídio como expressão de poder nas relações de gênero, em um contexto social atravessado pelos elevados índices de violência contra à mulher, cuja expressão mais brutal se materializa, cotidianamente, no feminicídio. No Brasil, os estudos que abordaram à violência contra à mulher, evidenciaram que altos índices de violência, a criminalização secundária ${ }^{3}$ e a degradação identitária das mulheres são fatores que geram insegurança e indignidade à elas.

Apesar do estado brasileiro ter constituído um sistema de proteção especial para eliminar todas às formas de discriminação, prevenir, punir e erradicar a violência contra à mulher, na sociedade brasileira, em consonância com a Convenção Interamericana para Prevenir, Punir e Erradicar a Violência contra a Mulher, editada pela Organização dos Estados Americanos (OEA), e a Convenção sobre a Eliminação de todas às formas de Discriminação Contra à Mulher/CEDAW, das quais o Brasil é signatário, a realização desse sistema protetivo depende de condições institucionais que permitam suas implementações. Inexistindo essas condições, restam apenas normas abstratas e textos prescritivos, normativamente emoldurados, que, concretamente, pouco contribuem para realizar às conquistas juridicamente consignadas.

Os estudos que abordaram esse tema, comprovaram a existência de uma realidade assustadora, expressa em estatísticas incompatíveis com uma

\footnotetext{
${ }^{3}$ Ao abordarem a vitimização e a criminalização da mulher na sociedade contemporânea, Cassol, Silva e Dinarte (2018) destacaram que, enquanto vítima da violência, particularmente à doméstica, a mulher é duplamente violentada. Primeiro pelo agressor, e, posteriormente, pelo sistema de justiça criminal, que integra a estrutura do Direito, e reproduz as relações de dominação masculina em uma sociedade atravessada pela desigual distribuição do poder. Diversamente da criminalização primária, que é deduzida da legislação penal, a criminalização secundária se realiza no curso da persecução penal, quando o crime é apurado e reprimido por instituições oficiais do Estado, tais como a Polícia e o Judiciário. Nesse curso, não raramente, há uma tendência a atribuir à vítima a responsabilidade pela pratica do crime, fragilizando sua posição da relação delitiva, tais como ocorre, por exemplo, quando a mulher é vítima de estupro, que além da rememoração, que lhe produz sofrimento e danos psicológicos, ainda é rotulada com responsável pela precipitação do crime com o seu comportamento
} 
sociedade que alcançou o processo civilizatório (PASINATO, 2010; GUSMÃO, GUSMÃO, 2017; GOMES, 2014). Uma sociedade na qual, apesar das constantes lutas, muitas mulheres ainda têm a dignidade negada, os corpos violados, e as vidas ceifadas, naturalmente, pelo fato de serem mulheres.

A coisificação das mulheres, bem como a naturalização da violação de seus direitos e garantias, modernamente conferidos, possui raízes históricas, fundadas nas ideias patriarcais, de natureza cultural, econômica, política, e ideológica, sobre às quais se soergue a diferenciação dos papéis sociais desenvolvidos por homens e mulheres. É com base nessas ideias arcaicas, reproduzidas nos processos interativos cotidianos, que, na sociedade brasileira, se legitima a distribuição desigual de um poder que hierarquiza os gêneros, forja identidades, e coloca à mulher no lugar da submissão.

É nesse contexto paradoxal de despersonalização e empoderamento da mulher, que o presente artigo tem como objetivo geral, contribuir com a reflexão sobre um quadro de banalização do horror, retocado com pinceladas do vermelho jorrado da brutal violência que, em seus diferentes tons, orna uma cruel realidade em toda sua textura, traduzida em lesões corporais, estupros, assédios e feminicídios. Especificamente, tem como objetivo a abordagem do feminicídio, em matiz transdisciplinar, particularmente, o jurídico e o sociológico. Trata-se de uma pesquisa qualitativa, fundada em diversas fontes de evidência, cujas principais foram a pesquisa bibliográfica, e o levantamento de dados correlatos à violência contra à a mulher.

Ante ao quadro composto, a violência contra a mulher constitui um tema atual, cuja relevância é irrefutável, visto que, paradoxalmente, às mulheres conquistam cada vez mais espaços sociais, na política, no mercado de trabalho e na mídia, ao mesmo tempo em que se reproduzem, intensamente, os atos de violência praticados contra elas, expressos em dados preocupantes.

\section{Véi, mulher feia não merece ser estuprada}


- Eu sou teu namorado, véi, quando eu pedir o celular você me dá o celular (...).

- Já te falei, véi, eu te pedi pra ver você não deixou, quando eu pedir pra ver você tem que me dá!

- Por que você é tão burra assim, véi? Para de fazer burrice, véi!

- Você não tem mais noção de porra nenhuma!

- Para de fazer burrice! Você não aceita um homem que tem mais dominância que você, você não aceita!

- Você acha que é o homem da relação, mas você não é! Você tem que aceitar que é uma mulher, véi.

- Tem que aceitar isso! (Jornal Nacional, 26/09/2018).

Essas frases foram pronunciadas em 23/09/2018, por Erick Bretz, após espancar violentamente Melissa Gents, na Flórida, Estados Unidos. Motivo do espancamento: ela se recusou a entregar o celular pessoal para o namorado vistoriá-lo. O vídeo foi apresentado no Jornal Nacional, transmitido pela Rede Globo e, à época, o caso teve grande repercussão na mídia brasileira. Bretz foi preso, pagou fiança de US\$60.000,00, e se encontra em liberdade aguardando julgamento nos Estados Unidos.

Essas palavras não são casuais, nem casuísticas, elas são forjadas e reproduzidas no berço de uma cultura que reduz a mulher ao espectro dos desejos masculinos, ao objeto que pode ser usado, dispensado ou mesmo destruído. Nesse contexto, em sua ritualização cotidiana, a coisificação da mulher é tão evidente, que nas palavras do atual presidente da República, Jair Bolsonaro, uma mulher feia não merece ser estuprada. Essa compreensão, foi expressa quando ele se dirigiu à deputada federal, Maria do Rosário, nos seguintes termos: "Ela não merece ser estuprada porque ela é muito ruim, porque ela é muito feia, não faz meu gênero, jamais a estupraria. Eu não sou estuprador, mas, se fosse, não iria estuprar porque não merece."

\footnotetext{
4 É fato notório que, por essas palavras, em 15/02/2017, a Terceira Turma do STJ manteve, por unanimidade, a condenação do, então, deputado federal, Jair Bolsonaro, pelas ofensas dirigidas à deputada Maria do Rosário, condenado a pagar indenização de $\mathrm{R} \$ 10$ mil à vítima, por danos morais, 
Nesses casos, deve-se observar que, às cenas enunciativas a assumem significados complexos, pois, envolvem valores e sentidos nem sempre percebidos à primeira análise, recolocando a violência contra à mulher em campo estruturado de forças e espaço público de produção de sentidos (Bourdieu, 1989), pois, é dessa forma que os fatos se condensam e ganham significados, reforçando às representações sociais da mulher, circulantes em determinados contextos sociais.

Consoante Bourdieu (1989), em suas relações cotidianas, desenvolvidas nos diversos espaços sociais, os indivíduos se utilizam de símbolos e significados, constituídos em um universo simbólico, organizado por meio de operações comunicativas, mobilizadoras de uma linguagem própria, que ao circular neste universo, torna-se referência na organização dos processos interativos, na percepção de si, do outro, e do ambiente circundante.

Nessa perspectiva, o compartilhamento de ideias, conhecimentos, e experiências baseadas em um plano interpessoal é estabelecido por meio da comunicação contínua entre os indivíduos, em um dado espaço social no qual são forjados os status ontológicos, e as identidades individuais e coletivas. Entretanto, nesses processos interativos, a comunicação não se reduz a transferência de significados de uma pessoa à outra, ou a mera transmissão passiva de informações, pois, nas relações interativas, a comunicação não emerge simplesmente de falas espontâneas. Ela pressupõe o exercício de habilidades cognitivas, e o envolvimento subjetivo entre pessoas que compartilham significados socialmente construídos (Bourdieu,1989).

Partindo desses pressupostos, às relações de subordinação e a desigual distribuição do poder entre gêneros são edificadas sobre um conjunto de ideias, imagens, e visões de mundo que os indivíduos constroem na vida cotidiana para compreenderem e organizarem suas relações. Isso significa, então, que a desqualificação da mulher é produzida nas atividades mais 
simples de elaboração psicológica e social da realidade, articulada à dinâmica dos processos interativos e cognitivos que possibilitam a comunicação entre os indivíduos e os grupos sociais, cuja dinâmica está associada às relações de poder (Bourdieu, 1989, 2003).

Segundo o autor, às dimensões físicas e simbólicas da violência configuram-se como expressões do exercício da subordinação social intergêneros, posto que, é nesse contexto mimético que o homem reproduz à lógica da dominação masculina, fundado no poder que "naturaliza" comportamentos violentos, legitimados por meio da aprendizagem e das repetições. Assim, a vulnerabilidade de gênero é moldada, consoante a construção das formas sociais e políticas de reprodução do poder.

Nesse sentido, os atos violentos praticados por Erick Bretz e Jair Bolsonaro oferecem quadros referenciais políticos e ideológicos, relativos às relações de gênero, conformadores de uma forma particular de compreender a realidade social, que traduz o mundo por meio de uma ordem significativa, que orientam suas práticas cotidianas. Nessa ordem, a mulher é convertida em objeto de disposição, e, se for feia, não merece nem ser estuprada.

Os enunciados desses indivíduos revelam apenas a camada mais tênue do substrato social, a partir do qual emergem os elementos mais complexos e dinâmicos de concreção da organização social, na qual se insere a lógica da violência cotidianamente praticada contra à mulher. A conduta dos agressores desvela um modo peculiar de elaboração da relação entre homem e mulher, por meio da qual eles reforçam e compartilham entre determinados grupos de homens, às representações sociais depreciativas da mulher.

Nessas representações, a mulher tem seu lugar bem definido, o da subalternidade, da obediência cega, portanto, deve entregar seu celular para que o "homem da relação" possa vistoriá-lo a qualquer momento que desejar. Da mesma forma, uma vez coisificada, a mulher pode, naturalmente, ser assediada, estuprada, e violada em seus direitos. Nessas construções 
cognitivas, resta à mulher, à insegurança, à indignidade e à submissão à violência praticada pelo homem.

Destarte, às palavras enunciadas por esses indivíduos explicitam o modo por meio do qual os sentidos se manifestam, e constroem, discursivamente, simulacros da realidade contextual, que ao serem compartilhados, legitimam, entre determinados grupos, a força violenta das representações sobre a qual é soerguida às bases de uma sociedade essencialmente machista, que oprime à mulher, colocando-a no lugar da indignidade, após ser concebida como fruto de uma "fraquejada", apesar de todos os avanços jurídicos e sociais conquistados com muita resistência.

Isso significa que, enunciar é fazer parte de um universo estruturado, no qual todos se colocam como sujeitos, frequentemente, em oposição e diálogo. Às palavras "Você acha que é o homem da relação, mas você não é! Você tem que aceitar que é uma mulher, véi", e "Ela não merece ser estuprada porque ela é muito ruim, porque ela é muito feia” são enunciadas por indivíduos de existência real, que percebem, sentem e expressam, por meio de enunciados, suas visões de mundo, e suas intenções em um campo estruturado de forças, no qual às relações de gênero são atravessadas pelo poder que institui o lugar social da mulher, a partir de uma memória social, que ideologicamente converge para um sentido específico, socialmente compartilhado (Bourdieu, 1989).

As palvras ditas por Bretz e Bolsonaro não devem ser apreendidos, ingenuamente, em suas realizações fragmentadas, como "brincadeiras", "desatinos" ou "espontaneidade do presidente", mas sim como expressão sombria de uma rede de relações concretas e essencialmente significativas, que traduzem e objetivam atos de uma dada realidade, marcada pelo desrespeito e, fundamentalmente, pela violência contra à mulher, expressa na celebração das lesões corporais dolosas, na naturalização do estupro, e na banalização feminicídio.

Isso porque, por meio de seus enunciados, os enunciadores legitimam, ideologicamente, a dominação da mulher pelo homem, à sua submissão, e à 
sua conversão em objeto de disposição, como se fosse uma propriedade, sem direito de dizer "não" ao seu proprietário. Essa mentalidade, forjada ao longo de séculos, contribui significativamente para coisificação do direito à vida da mulher, que fica exposta ao seu arbítrio de seu proprietário, o que é inadmissível em uma sociedade na qual se luta pelo respeito à dignidade de todos indivíduos, independente de sexo ou gênero.

\section{Aspectos da violência contra à mulher}

Os estudos que abordam o crime de homicídio, praticado contra mulheres, cuja motivação relaciona-se ao gênero feminino, ou que resultam da violência constituída nas relações domésticas, evidenciaram que a incidência de feminicídio tem aumentado significativamente, em âmbito internacional e nacional ${ }^{5}$.

Em 2011, a Secretaria de Políticas para as Mulheres, vinculadas a Presidência da República, redimensionou o "Pacto Nacional pelo Enfrentamento a Violência contra as Mulheres6", com os objetivos de ampliar, fortalecer e integras as ações estatais (união, estados e municípios) dirigidas ao enfrentamento da violência contra as mulheres, por meio da criação de normas e padrões de atendimento, aperfeiçoamento da legislação, incentivo a constituição de redes de serviços, o apoio a projetos educativos e culturais de prevenção à violência, e ampliação do acesso das mulheres a justiça e aos serviços de segurança pública (Brasil, 2011).

Apesar da sanção da Lei Maria da Penha, da criação de delegacias e vara criminais especializadas, da tipificação do feminicídio, como circunstância qualificadora do homicídio, a violência contra as mulheres continua com índices elevados. Os estudos empíricos que abordam o tema,

\footnotetext{
${ }_{5}^{5}$ Nesse sentido: Staudt (2011), Pasinato (2010, 2011), Gomes (2014), Meneghel e Hirakata (2011), e Hirakata (2014), Bianchini (2016a) entre outros.

${ }^{6}$ O Pacto Nacional de Enfretamento a Violência Contra a Mulher foi criado em agosto de 2007, um ano após a sanção da Lei Maria da Penha, com a finalidade de articular ações dirigidas a consolidação da Política Nacional de Enfrentamento a Violência contra as Mulheres, por meio da implementação de políticas públicas integradas em todo o território nacional.
} 
desenvolvidos com base em pesquisas estatísticas, na análise de conteúdo, e os trabalhos de natureza histórico-descritiva evidenciaram que as políticas públicas desenvolvidas no Brasil, ainda são insuficientes para superação desse problema, que é de ordem pública

Ao desenvolver um estudo exaustivo sobre as dinâmicas sociais que envolvem a alta incidência de homicídios de mulheres no estado do Pernambuco, Gomes (2014) demonstrou que os contextos dos homicídios de mulheres são diversificados e obedecem a dinâmicas sociais distintas, nas quais o gênero sempre aparece como vetor ativo, mas, ressalta sua variação na prática delitiva. Esse achado, exige do pesquisador novos desafios teóricos para compreender os modos de articulação entre contextos tradicionais e atuais de violência contra as mulheres, e, paralelamente, impõe a necessidade de revisão das políticas públicas, que articulam o campo da segurança pública e as políticas de contenção dessa espécis de violência.

Os estudos desenvolvidos por Hirakata (2011, 2014), demostraram que, no Brasil, mais da metade dos homicídios praticados contra mulheres são qualificados como femicídios, cujas causas estão intimamente relacionadas às desigualdades de gênero. Segundo a autora, esse fenômeno apresenta dimensões intercontinentais, à medidade que é evidenciado na Europa,

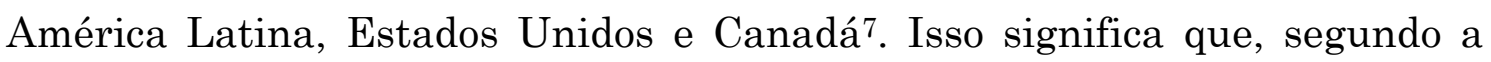
autora, feminicídio possui um padrão, que se repete na maioria dos países, indicando que as mulheres são muito mais vulneráveis que os homens ao risco de serem mortas por parceiros íntimos.

No Brasil, diariamente, um número significativo de mulheres, jovens e adolescentes, são submetidas a algum tipo de violência relacionada ao gênero feminino, tais como lesões corporais, estupro, torturas, assédio, exploração sexual, e, mais trágica de todas, o feminicídio. No dia 4 de fevereiro de 2019, a Comissão Interamericana de Direitos Humanos (CIDH) manifestou, por meio de nota publicada, a preocupação quanto à elevada incidência de assassinatos de mulheres

\footnotetext{
${ }^{7}$ No mesmo sentido é o estudo desenvolvido por WAISELFISZ (2015).
} 
ocorridas no país ${ }^{8}$. Consoante os dados do Monitor da violência, entre 2016 e 2019, foram registrados, no país, 4.349 feminicídios, sendo que as vítimas, em sua maior parte, eram mulheres jovens, entre 20 e 39 anos. No estado do Pará, foram 203 vítimas ${ }^{9}$.

De acordo com o relatório anual do Fórum Brasileiro de Segurança Pública (FBSP), entre 2017 e 2018, às mulheres foram vítimas de 515.962 lesões corporais, dolosas, praticadas em ambiente doméstico. No Estado do Pará foram 14.596 casos registrados. Nesse mesmo período, ocorreram, ainda, no Brasil, 104.324 casos de estupros, sendo 6.254 no Pará. 10

Ainda, segundo a FBSP, entre março e abril de 2020, durante o isolamento da pandemia decorrente da Covid-19, no Brasil, foram registrados 19.809 estupros ${ }^{11}$, e 143 feminicídios, sendo 10 registrados no Pará. No mesmo período foram registradas 29.610 lesões corporais, dolosas, em ambiente domésticos, das quais 653 ocorreram no Pará. ${ }^{12}$

Em recente estudo sobre a violência contra a mulher em período de isolamento social, Viera, Garcia e Maciel (2020) concluíram que, apesar de haver, ainda, dados incipientes sobre a temática, as notícias divulgadas na mídia e nos relatórios de organizações internacionais, tais como a ONU, evidenciam que, após a implementação do isolamento social imposto pelos Estados em decorrência da pandemia da Covid-19, a violência contra a mulher revelou mais uma tonalidade de sua face brutal, qual seja, os registros policiais de agressões contra as mulheres em ambiente doméstico triplicaram em países como a China, Itália, França e Espanha evidenciando a composição de um quadro universal, pintado com as mãos da opressão masculina, que, não raramente, produzem o feminicídio. Nessa cena dantesca, a mulher é

\footnotetext{
8< http://www.oas.org/pt/cidh/prensa/notas/2019/024.asp>. Acesso em 17 ju. 2020.

${ }_{9}$ Disponível em: <g1.globo.com/monitor-da-violencia/noticia/2020/03/05/mesmo-com-queda-recorde-demortes-de-mulheres-brasil-tem-alta-no-numero-de-feminicidios-em-2019.ghtml>. Acesso em 20 abr. 2020.

10 Disponível em: Conferir em: <http://www.forumseguranca.org.br/wpcontent/uploads/2019/09/Anuario-2019-FINAL-v3.pdf>. Acesso em 10 fev. 2020.

11 Nesse relatório não foram incluídos os estudos ocorridos no estado Pará.

12 Disponível em: <https://forumseguranca.org.br/wp-content/uploads/2020/06/violencia-domesticacovid-19-ed02-v5.pdf>. Acesso 17 jun. 2020.
} 
destituída da cidadania que constitucionalmente a reveste, para ser convertida em o objeto de opressão masculina.

De acordo com Ouvidoria Nacional dos Direitos Humanos, do Ministério da Mulher, da Família e dos Direitos Humanos, entre os dias 1 e 25 de março de 2020, houve um crescimento de 18\% no número de denúncias registradas pelos serviços disque 100 e ligue $180^{13}$. É uma expressão bárbara, mas real e reveladora da violência contra a mulher em toda sua magnitude. Neste contexto, é comum que as mulheres estejam expostas ao perigo, enquanto são obrigadas a se recolherem ao ambiente doméstico.

A violência contra à mulher não se reduz a números, ela tem nomes, produz sofrimento, dor, morte física para a vítima, e morte simbólica para filhos, parentes e amigos da vítima. No dia 08/09/2018, Wiliana Oliveira da Silva, de 24 anos, foi assassinada pelo marido, no condomínio Vale da Prata, no bairro Camboatã, no município de Paragominas/PA. Em 05/09/2018, a editora paraense, Simone Aparecida Pereira, de 35 anos, foi assassinada a facadas, em Nova Marabá, pelo próprio marido. No dia 07/09/2018, Ivone Siqueira foi morta pelo companheiro, com cinco facadas no pescoço, na rua da Brasília, no bairro Recanto Verde, em Icoaraci, distrito de Belém. Em 15/07/2018, Ana Paula Gomes do Nascimento, 32 anos, foi assassinada pelo companheiro à facadas, na Praça Matriz da Vila de Mosqueiro, próximo ao Terminal Rodoviário do distrito de Mosqueiro. Em 19/04/2018, uma mulher, conhecida como Silvana, foi assassinada pelo companheiro, com uma facada no peito, no município de Marituba, Região Metropolitana de Belém ${ }^{14}$.

Em 15/01/2018, Deusiane Araújo Conceição, 27 anos, foi morta pelo marido, dentro de casa, no município de Altamira, por uma simples razão: resolveu se insurgir contra as constantes agressões e os sofrimentos impostos pelo cônjuge, e separar-se do agressor ${ }^{15}$. Ao nominar essa violência, somente

\footnotetext{
${ }^{13}$ Disponível em:< https://www.gov. br/mdh/pt-br/assuntos/noticias/2020-2/marco/ coronavirus-sobe-onumero-de-ligacoes-para-canalde-denuncia-de-violencia-domestica-na-quarentena>. Acesso em 20 abr. 2020.

14 Disponível em: <www.diarioonline.com.br/noticias/policia/noticia-538198-mulher-e-assassinada-atiros-pelo-marido-em-paragominas.html>. Consulta em 01 out. 2018

15 Idem.
} 
com o nome das vítimas, poder-se-ia preencher centenas de páginas com notícias de assassinatos, e violência sórdida das mais diversas formas sofridas por mulheres brasileiras, impostas por "maridos", "companheiros", "namorados", "agentes públicos", entre outros.

De acordo com Bianchini (2016), a sociedade brasileira é, ainda, caracterizada pelo desrespeito aos direitos fundamentais da mulher, assegurados pela pretendida igualdade consignada no caput do artigo $5^{\circ}$ da Constituição Federal (Brasil, 1988), pela Convenção sobre a Eliminação de Todas as Formas de Violência contra a Mulher, e, sobretudo, pela Convenção Interamericana para Prevenir, Punir e Erradicar a Violência contra a Mulher.

Os estudos que abordam à violência contra à mulher evidenciam que o respeito às mulheres não é inviabilizado pela falta de normas jurídicas, mas em virtude da posição que elas ocupam no espaço social, posição essa, objetivada com base em representações sociais, cujos significados estruturantes da relação de gênero são forjados com significantes de matizes preconceituosos e depreciativos.

O sistema de proteção especial, edificado pelo Estado brasileiro para promover o respeito e a efetiva proteção à mulher, contra todas às formas de discriminação e violência, constitui um microssistema de proteção que ampliou e consolidou a matéria jurídica relativa ao tema, cujos principais pilares são à Lei Maria da Penha (Brasil, 2006), o Decreto n. ${ }^{\circ}$ 89.460/1984, que promulgou à Convenção sobre a Eliminação de todas às formas de Discriminação Contra à Mulher/CEDAW,1979 (Brasil, 1984), e o Decreto ${ }^{\circ}$ 1.973/1996, que promulgou a Convenção Interamericana para Prevenir, Punir e Erradicar a Violência contra a Mulher, Belém do Pará, 09/06/1994 (Brasil, 1996).

Entretanto, o respeito, a efetiva proteção, e a eliminação de todas às formas de discriminação e violência contra à mulher dependem de condições institucionais que permitam suas implementações. Inexistindo essas condições, restam apenas textos prescritivos, compostos por mandamentos proibitivos, emoldurados normativamente, que, objetivamente, pouco 
contribuem para realizar às conquistas juridicamente consignadas, posto que, discrepam da realidade expressa em estatísticas grotescas, que se reduzem aos números, mas à dignidades negadas, à corpos violados, e à milhares de vidas ceifadas pelo fato de serem mulheres.

Segundo Pasinato (2011), às altas incidências de feminicídio, constitui um fenômeno mundial, pois é verificado em diversos países, nos mais diferentes contextos sociais e culturais, tratando-se, portanto, como as demais formas de violência contra à mulher, apresenta um caráter universal e estrutural, fundado no sistema de dominação masculina, predominante em quase a totalidade das sociedades ocidentais.

Partindo desses pressupostos, a autora entende que o feminicídio se expressa como resultado da assimetria que se estabelece nas relações de poder constituídas entre homens e mulheres, ao mesmo tempo em que pode reforçar a manutenção e reprodução dessas diferenças, se não houver à formulação de políticas pública e desenvolvimento ações estatais dirigidas não só para aumentar penas e estabelecer punições mais rigorosa, mas, também, para criar uma ampla rede de suporte às mulheres vítimas da violência de gênero, bem como a superar a mentalidade, ainda dominante na sociedade brasileira, que rege as relações de gênero.

\section{O conceito de feminicídio}

O feminicídio constitui uma qualificadora do homicídio, tipificada no art. $121 \S 2^{\circ}$, VI, do Código Penal Brasileiro (Brasil, 1940). Nessa hipótese normativa, à prática do homicídio é adicionada uma circunstância especial, qual seja, a conduta é conscientemente dirigida a matar uma "mulher", impelida por razões da condição de "sexo feminino".

\section{"Homicídio simples}

Art. 121 - Matar alguém

Pena - reclusão, de 6 (seis) a 20 (vinte) anos. 
(...)

Homicídio qualificado

$\S 2^{o}$ - Se o homicídio é cometido:

(...)

VI - contra a mulher por razões da condição de sexo feminino:

(...).

Pena - reclusão, de 12 (doze) a 30 (trinta) anos.”

O Inciso IV foi incluído ao $§ 2^{\circ}$ do art. 121, por meio da Lei 13.104 de 09/03/2015 (Brasil, 2015). Desde que entrou em vigor, esse dispositivo gerou controvérsias na doutrina e na jurisprudência, entre às quais, à relativa à natureza objetiva ou subjetiva da qualificadora do feminicídio, que ainda não foram totalmente resolvidas. A qualificadora se refere ao homicídio praticado contra "mulher", cuja motivação determinante é pertencer ao "sexo feminino". Portanto, antes de entrar no mérito de qualquer controvérsia sobre a circunstância qualificadora, preliminarmente, faz-se relevante esclarecer a diferença entre os termos "mulher" e "sexo feminino", que, não raramente, são empregados como termos sinônimos, quando, não os são.

Consoante Hirata (2014), o sexo se refere às categorias inatas, e possui pressupostos biológicos, relacionados ao dimorfismo sexual, classificando-se em masculino e feminino. Diversamente, o gênero possui pressupostos sociais e culturais referentes ao acervo identitário dos indivíduos, e aos papeis sociais, contextualmente desenvolvidos por mulheres e homens. Os estudos desenvolvidos no campo da Sociologia e da Antropologia evidenciaram que todas às sociedades são atravessadas por diferenças de gênero, posto que, nelas, há uma pluralidade de papéis socialmente instituídos para homens e mulheres, cujas representações refletem às contradições das condições materiais de existência, às formas de organização política, econômica e ideológica, que se modificam no curso do tempo, no espaço e na história (Hirata, 2014). 
Essa distinção é importante porque revela, parcialmente, a oposição fundante entre natureza e cultura. Isso significa que à submissão das mulheres à papéis desqualificados e desumanizantes, tais como, o da "mulher intelectualmente incapaz", "fisicamente frágil", ou que foi "criada com parte da costela de Adão para satisfazer ao homem", é determinado culturalmente, e não por vetores de ordem biológica (Resador, Rios, 2018). Em suma, sexo é uma categoria que possui pressupostos biológicos, e o gênero possui pressupostos sociais e culturais, sendo que os pressupostos biológicos e culturais se incorporam ao acervo identitário dos indivíduos.

Ocorre, porém, que nem sempre os papéis sociais definidos em razão do gênero estão em consonância com a identidade sexual dos indivíduos. Isso porque, não raramente, há indivíduos que nascem com a genitália masculina, mas se identificam como mulheres. Da mesma forma, há indivíduos que nascem com genitália feminina e se identificam como homens. São os chamados transgêneros. Isso significa que a identidade de gênero está associada ao sentimento de ser mulher, e ao sentimento de ser homem, independente das características anátomo-fisiológicas que definem o sexo masculino e feminino, conforme se deduz da frase elaborada por Simone de Beauvoir, amplamente difundida na sociedade contemporânea, na qual conclui que "ninguém nasce mulher, torna-se mulher". Portanto, uma mulher pode se identificar como pertencente ao sexo masculino, da mesma forma que um homem pode se sentir do sexo feminino, com base no sentimento de pertença, nas atitudes e na concepção de mundo, isto é, no critério de autodeclaração.

Indubitavelmente, às questões concernentes à identificação do sexo e do gênero, bem como às relativas à transexualidade e ao transgênero são importantes para abordagem do feminicídio, pois, em muitos casos, podem repercutir na adequação tipificação da conduta delitiva ${ }^{16}$. Entretanto, consoante Resador e Rios (2018), a abordagem da autodeclaração referentes

16 Nesse sentido consultar Gerbrim e Borges (2014). 
às identidades sexuais e de gênero, requer um exame profundo da sua previsão normativa no direito brasileiro, visto que essa técnica de identificação está associada, particularmente, a identificação étnico-racial de índios e quilombolas. Assim, segundo os autores, no Brasil, há, ainda, vazio normativo dirigido a regulamentar a complexidade e a dinâmica da autodeclaração, relativas ao sexo e ao gênero.

Apesar da controvérsia sobre o conceito de mulher e sua extensão aos transgêneros, transexuais e travestis na hipótese do feminicídio, posto que o $\S 2^{\circ}$ da lei Lei 13.104/2015, considera que há razões de condição de sexo feminino quando o crime envolve, violência doméstica e familiar, ou quando há o menosprezo ou discriminação à condição de mulher (Brasil, 2015), o presente artigo tem como principal objetivo abordar a violência contra a mulher, do sexo feminino, com base nas estatísticas oficiais. Isso porque, há diferença na forma como a violência se expressa quando é praticada contra homem que se identifica sexualmente como pertencente ao sexo feminino, e se coloca socialmente como mulher, em uma relação de alteridade. Situações como essa, exigem um estudo específico sobre o assassinato de mulheres trans, e, por fatores de ordem prática, será desenvolvido em outro momento.

Consoante Bento (2014), a população transgênero constitui-se como grupos de indivíduos, historicamente lançados em uma zona obscura do convívio social, relacionados, particularmente, à prostituição. Em seus estudos, a autora evidenciou que nos assassinatos praticados contra as mulheres, as agressões geralmente ocorrem no ambiente doméstico, em casa, e os agentes são os companheiros ou ex-companheiros, resultando em processos criminais, com prolação de sentença condenatória. Diversamente, as mulheres trans são barbaramente assassinadas à rua, por desconhecidos, sendo que, $90 \%$ dos casos não chegam a fase processual. Assim, o conceito de feminicídio, na forma como foi legalmente concebido, é insuficiente para compreender as especificidades do assassinato de mulheres trans.

Partindo desses pressupostos, Bento (2014) concebe o transfeminício como uma ação ontologicamente ordenada, conscientemente dirigida a 
eliminar a população trans no Brasil, motivada pelo sentimento de ódio e nojo. Para delimitar o transfeminicídio e diferenciá-lo do feminicídio, a autora apresenta seis vetores, quais sejam, (1) o assassinato é motivado pelo gênero e não pela sexualidade da vítima, (2) a morte é ritualizada, com a mutilação dos corpos, por meio de dezenas de facadas, ou por diversos disparos de arma de fogo, (3) ausência de processos criminais, que expressa a negação da existência da população trans, associada ao desejos de sua eliminação na sociedade brasileira, (4) as famílias das pessoas trans, raramente reclamam os corpos, (5) suas identidades de gênero não são respeitadas no noticiário da morte, na preparação do corpo e no registro da morte, e, por fim, (6) os assassinatos são praticados duante a noite, em espaços públicos, principalmente nas ruas desertas.

Segundo Barros e Souza (2019), o feminicídio é o termo empregado para denominar o assassinato de mulheres, cometidos em razão do gênero, ou derivados da violência constituída nas relações domésticas, nos termos da Lei Maria da Penha (Brasil, 2006). Segundo os autores, essa palavra foi cunhada pela socióloga sul-africana Diana Russell, e se popularizou a partir 1976, quando foi apresentada no Simpósio do Tribunal Internacional de Crimes contra Mulheres, realizado em Bruxelas, na Bélgica. Russell, elaborou o conceito a partir da palavra "fêmea", significando homicídio de fêmeas. Dessa forma, usou o termo feminicídio para diferenciá-lo do homicídio, que se caracteriza como um tipo de natureza geral, materializado na conduta "matar alguém”, ou seja, qualquer pessoa, incluindo-se crianças, idosos, e as mulheres. Nessa perspectiva, a conduta matar uma mulher em razão do gênero, constitui uma situação particular, devendo, portanto, ser tratada com suas peculiaridades, imputando-se penas mais rigorosas, em razão de sua maior reprovação social.

Consoante Meneghel e Portella (2017), a diferença entre os crimes de homicídio e feminicídio, transcende os efeitos penais da conduta "matar alguém”, tipificada no art. 121 do CPB. O primeiro realiza-se, tão somente, como um assassinato, cuja vítima também pode ser uma mulher. Por sua vez, 
o segundo, refere-se à destruição da vida de uma mulher, fundado nas razões de gênero, configurando crime de lesa humanidade, ou seja, a mulher é assassinada por ser mulher, e se insurgir contra às correntes físicas ou simbólicas que produzem a mortificação do eu feminino (Goffman, 2008).

Isso significa dizer, então, que no conceito feminicídio se inscreve, não somente a destruição da vida de uma mulher, nele, há um série de sentidos objetivos e subjetivos relacionados à circunstância qualificadora, que estão em movimento, tais como, o assassinato de mulheres praticado por homens impelidos pelo ódio, desprezo, prazer, pelo egoístico sentimento de posse, de vingança, e o que é mais grave, pela negação da condição da mulher como um ser vivo, independente, e capaz de decidir sobre sua própria vida. Enfim, não há como pensar o feminicídio sem dimensionar seus aspectos tipológicos, políticos, econômicos, culturais, e ideológicos constituídos em uma sociedade marcada pela desigual distribuição do poder entre homens e mulheres (Meneghel e Portella, 2017).

No mesmo sentido, Barros e Souza (2019) entendem que a tipificação da circunstância qualificadora que configura o feminicídio, está associada ao assassinato da mulher, praticado pelo homem, motivado por misógina e ódio às mulheres. Dessa forma, esse tipo de crime situa-se na extremidade do contínuo de terror, dirigido ao controle da mulher nas diversas sociedades, no qual se incluem as agressões físicas e verbais, o estupro, a tortura, o abuso sexual, espancamento físico e emocional, assédio sexual, mutilação genital, a proibição de conduzir veículo automotor, a legitimação do apedrejamento de mulheres, privação de comida para mulheres em algumas culturas entre outras formas de opressão feminina.

Apesar de possuir múltiplas dimensões, juridicamente, o feminicídio pode ser definido como uma circunstância qualificadora específica do crime de homicídio, subjetivamente relacionada ao ódio contra às mulheres, na qual a prática do homicídio tem como elemento central, a mulher na condição de sexo feminino. Entre essas circunstâncias, incluem-se os assassinatos em contexto de violência doméstica. Simbolicamente, esses tipos de crimes desvelam a 
destruição da identidade da vítima, e de sua condição de mulher, que em geral, reage a sua opressão.

Para Gusmão e Dornelles (2017), há o incremento do feminicídio quando o Estado não desenvolve políticas públicas eficazes para combater a opressão das mulheres, não lhes dá garantias, e não cria condições de segurança para suas vidas na comunidade, em suas casas, nos espaços de trabalho e de lazer. Enfim, a violência se agudiza mais ainda, quando as autoridades públicas não realizam, com eficiência, suas funções. Isto posto, segundo o autor, o feminicídio pode ser configurado como um crime de Estado. Indubitavelmente, o uso da qualificadora facilita a sistematização de evidências da violência contra mulher, pois, a diferenciação entre o homicídio e o feminicídio, com base na relação de gênero, confere-se uma dimensão política e social a este problema, evidenciando a necessidade de implementação de políticas públicas, de abrangência coletiva (Bianchini, 2016).

\section{Importância da qualificadora}

Antes da promulgação da Lei n. ${ }^{\circ} 13.104 / 2015$, a morte de mulheres em razão de gênero era computada nas estatísticas oficiais como homicídio, sem dimensionar às especificidades das motivações especiais, e do contexto relacional no qual o crime é praticado.

A discriminação da mulher, possui raízes nas ideias patriarcais, sobre às quais se soergue a diferenciação nos papéis sociais desenvolvidos por homens e mulheres, fundada na distribuição desigual de um poder que hierarquiza os gêneros, colocando à mulher no lugar da subalternidade. Essa relação de subordinação entre os gêneros é importante para compreender à violência doméstica e, consequentemente, o feminicídio, pois, suas causas estão intimamente relacionadas a resistência da mulher à naturalização da violência, e a sua luta pela realização de seus direitos, de decidir sobre sua 
vida com independência, sem estar submetidas às ordens do patriarca, personificado no "homem da relação".

Obviamente que matar uma mulher, por motivo de ser ela uma mulher, colocando-a no plano da insignificância humana, poderia ser considerada uma conduta praticada com requintes de torpeza, constituindo um homicídio qualificado, por motivo torpe, consoante previsão do inciso I do $\S 2^{\circ}$ do art. 121 do CPB. Ocorre, porém, que questão não é esta. Deve-se observar que, o feminicídio possui matizes de natureza jurídica, política, ideológica e cultural, estreitamente articulados prevenção, punição e erradicação de todas às formas de violência praticadas contra à mulher, em razão de gênero.

Nesse sentido, faz-se relevante destacar que, apesar de relacionar à qualificadora ao gênero, o feminicídio não prevê à fragilidade da mulher como seu elemento integrativo, posto que, a configuração do dispositivo exige que, ao praticar o homicídio, o agente pratique a conduta, impelido pelo sentimento de desprezo em relação ao gênero. Nesse caso, diferente da classificação tradicional, na qual, o homem é concebido como superior, mais forte e mais poderoso, cabendo-lhe conferir proteção à mulher, concebida como "sexo frágil”, a incriminação especial, prevista no inciso VI inciso I do $\S 2^{\circ}$ do art. 121 do CPB, não é dirigida a reproduzir e reforçar esses pressupostos, mas, fundamental, reprimir e prevenir este tipo de discriminação contra à mulher, em consonância com a Convenção Interamericana para Prevenir, Punir e Erradicar a Violência contra a Mulher, também conhecido como Convenção de Belém do Pará, editada pela Organização dos Estados Americanos - OEA, em 1994, da qual o Brasil é signatário.

Sabe-se que nem sempre o assassinato de uma mulher configura feminicídio. Segundo dados, do FBSP, entre 2017 e 2018, no Brasil ocorreram 10.966 homicídios praticados contra mulheres, dos quais 2.357 foram qualificados como feminicídio ${ }^{17}$. Portanto, essa diferenciação é importante,

\footnotetext{
${ }^{17}$ Disponível em: Conferir em: $<$ http://www.forumseguranca.org.br/wp-content/uploads/2019/09/Anuario2019-FINAL-v3.pdf $>$.
} 
também, para produzir informações indispensáveis à elaboração de políticas públicas dirigidas à erradicação da discriminação da mulher na sociedade brasileira, bem como para combater à violência doméstica.

O estudo desenvolvido por Bianchini (2016), evidenciou que desde o início de sua vigência, a Lei 13.104/2005 gerou controvérsias na doutrina e na jurisprudência sobre à natureza objetiva ou subjetiva da circunstância qualificadora, constitutiva do feminicídio. Pois, para configurar feminicídio não basta que a vítima seja uma mulher. A morte deve ocorrer por "razões de condição de sexo feminino", ou estar associada à prática de violência doméstica e familiar, prefigurada no art. $5^{\circ}$ da Lei Maria da Penha (Brasil, 2006), conceituada como "qualquer ação ou omissão baseada no gênero que the cause morte, lesão, sofrimento físico, sexual ou psicológico e dano moral ou patrimonial".

Todavia, apesar da controvérsia, no julgamento do Recurso Especial n. $^{\circ}$ 1.795.892/RN, em setembro de 2019, relatado pelo Ministro, Joel Ilan Paciornik, a Quinta Turma do STJ reiterou o seu entendimento, segundo o qual, a natureza da circunstância é objetiva.

AGRAVO REGIMENTAL EM AGRAVO EM RECURSO ESPECIAL. HOMICÍDIO QUALIFICADO. SENTENÇA DE PRONÚNCIA. MEIO QUE DIFICULTOU A DEFESA DA VÍTIMA E FEMINICÍDIO. PLEITO DE AFASTAMENTO DAS QUALIFICADORAS. ALEGADA AUSENNCIA DE CONGRUÊNCIA LÓGICA COM OS TERMOS DA ACUSAÇÃO. TESE DEFENSIVA NÃO DEBATIDA NAS INSTÂNCIAS ORDINÁRIAS SOB ESSE PRISMA. SÚMULAS 282 E 356/STF. INEXISTÊNCIA DE PROVA ACERCA DA MOTIVAÇÃO RELACIONADA À CONDIÇÃO DE SER MULHER. IRRELEVÂNCIA. ÂNIMO DO AGENTE. ANÁLISE DISPENSÁVEL DADA A NATUREZA OBJETIVA DO FEMINICÍDIO. PRECEDENTES. ALEGAÇÃO DE EXCESSO DE LINGUAGEM. NÃO OCORRENNCIA.

(...) 
2. A jurisprudência desta Corte de Justiça firmou o entendimento segundo o qual o feminicídio possui natureza objetiva ${ }^{18}$, pois incide nos crimes praticados contra a mulher por razão do seu gênero feminino e/ou sempre que o crime estiver atrelado à violência doméstica e familiar propriamente dita, assim o animus do agente não é objeto de análise (AgRg no REsp n. 1.741.418/SP, Reynaldo Soares da Fonseca, Quinta Turma, DJe $15 / 6 / 2018)$.

(...).

4. Agravo regimental improvido.

(STJ: 1454781, Relator: Ministro Sebastião Reis Júnior, J.: 17/12/2019, T6 - Sexta Turma, P.: 19/12/2019)

Esse entendimento tem sido amplamente adotado nos julgados realizados em diversos tribunais brasileiros, e, sua tendência é consolidar-se na jurisprudência pátria.

\section{Considerações finais}

O feminicídio não se reduz, tão somente, aos termos, matar uma mulher, "por razões da condição de sexo feminino", que se realiza como uma das formas de expressão da violência doméstica. A instituição do feminicídio está relacionado a ideia de opressão, desigualdade, dominação e poder, que estruturam às relações de gênero constituídas na sociedade brasileira. A sua diferenciação do homicídio configura-se, então, como um importante instrumento para se conhecer, com mais densidade, à violência contra à mulher, em sua forma mais brutal, bem como, enfrentar a naturalização e a banalização da violência sofrida por elas.

A pesquisa se soma aos demais estudos desenvolvidos por pesquisadores de diversas área do conhecimento, ao concluir que, em pleno século XXI, apesar de todos os avanços tecnológicos, da Lei Maria da Penha e

\footnotetext{
${ }^{18}$ Grifo nosso.
} 
da Convenção Interamericana para Prevenir, Punir e Erradicar a Violência contra a Mulher, no Brasil, as mulheres, em sua maioria, continuam oprimidas, recebendo tratamento desigual, em uma sociedade constituída com base em modelos preconceituosos que produzem e reproduzem a depreciação social e política da mulher

Os sentidos da violência se expressam nas mortes da Wiliana, Ivone, Ana Paula, Silvana, Deusiane, além de outras milhares de mulheres que, nos últimos anos, foram assassinadas neste país. Ocorre, porém, que esses feminicídios tem sua origem em reiteradas ações comunicativas, sejam elas "irônicas", "engraçadas" ou "espontâneas", que, ao serem compartilhadas cotidianamente, por meio de um processo de subjetivação, disseminam à discriminação, reforçam o preconceito, e reproduzem naturalmente a degradação identitária da mulher.

Esse processo ganha vida nos diversos espaços relacionais e enunciativos, sejam reais ou virtuais, nos quais há a manifestação de valores sociais que marcam a sociedade brasileira, contribuindo para o fortalecimento da distribuição desigual de poder, com base na hierarquia de gênero.

O compartilhamento de ideais preconceituosas e estereotipadas, projetadas sobre às mulheres, realiza-se de diversas formas, tais por meio de piadas, novelas, músicas, entre outras. Quando se ensina a uma criança, do sexo masculino, que "o mês de fevereiro é o mês que às mulheres falam menos, porque tem menos dias", e ela reproduz a "piadinha", facilmente aprendida, para outras crianças na escola, dá-se, espontaneamente, os primeiros passos em direção à zombaria da mulher, que, posteriormente, pode evoluir para uma violência simbólica, expressa nos termos, "se mulher prestasse para alguma coisa, haveria uma na santa ceia", chegando a negação da cidadania que a reveste, expressa nas lesões corporais, na violência psicológica e, até mesmo, a naturalização do feminicídio.

Por fim, vale lembrar um conhecido adágio, atribuído a Pitágoras: "Eduquem às crianças, para que não seja necessário punir os adultos". Educar às crianças é um dos caminhos para eliminar todas às formas de 
discriminação contra à mulher, bem como prevenir, punir e erradicar a violência contra a elas.

\section{Referências}

BARROS, Francisco D., SOUZA. Renné O. Feminicídio: controvérsia e aspectos práticos. São Paulo: JH Mizuno, 2019.

BENTO, Berenice. Brasil: país do transfeminicídio. Centro Latino-Americano em sexualidade e Direitos Humanos. Rio de Janeiro, 04/06/2014. Disponível em:

$<$ http://www.clam.org.br/uploads/arquivo/Transfeminicidio_Berenice_Bento.pdf $>$. Acesso em: 03 jul. 2020.

BIANCHINI, Alice . A Qualificadora do Feminicídio é de Natureza Objetiva ou Subjetiva? Alice Bianchini. Revista EMERJ, Rio de Janeiro, v. 19, n. 72, p. 203 - 219, jan/mar. $2016 . \quad$ Disponível em: <www.tjse.jus.br/portaldamulher/arquivos/documentos/artigos/feminicidio.pdf $>$. Acesso em: 17 mar. 2020.

Lei Maria da Penha. Lei n. 11.340/2006: aspectos assistenciais, protetivos, criminais da violência de gênero. São Paulo: Saraiva, 2016a.

BOURDIEU, Pierre. O Poder Simbólico. Lisboa/Rio de Janeiro: Difel/Bertrand Brasil, 1989.

A dominação masculina. (3 ${ }^{\text {a }}$ ed.) Rio de Janeiro: Bertrand Brasil, 2003.

BRASIL (1940). Decreto-Lei 2.848, de 07 de dezembro de 1940. Código Penal. Disponível em: <www.legjur.com.br>. Acesso em: 12 jun.2020. 
BRASIL (1984). Decreto $n .^{\circ}$ 89.460/1984, de 20 de março de 1984. Dispõe sobre à Convenção sobre a Eliminação de todas às formas de Discriminação Contra à Mulher. Disponível em: <www.legjur.com.br>. Acesso em: 12 jun.2019.

BRASIL (1988). Constituição da República Federativa do Brasil, 1988. Disponível em: <www.legjur.com.br Acesso em: 12/06/2019>.

BRASIL (1996). Decreto $n^{\circ} 1.973 / 1996$, de 01 de agosto de 1996. Dispõe sobre à Convenção Interamericana para Prevenir, Punir e Erradicar a Violência contra a Mulher. Disponível em: <www.legjur.com.br>. Acesso em: 12 jun. 2019.

BRASIL (2006). Lei $n^{\circ} 11.340$, de 7 de agosto de 2006. Lei Maria da Penha. Disponível em: Disponível em: www.legjur.com.br Acesso em: 12/06/2019.

BRASIL (2015). Lei $n^{\circ}$ 13.104, de 03 de março de 2015. Altera o art. 121 do DecretoLei $\mathrm{n}^{0}$ 2.848, de 7/12/1940 - Código Penal, para prever o feminicídio como circunstância qualificadora do crime de homicídio, e o art. $1^{\circ}$ da Lei ${ }^{\circ} 8.072$, de 25 de julho de 1990, para incluir o feminicídio no rol dos crimes hediondos. Disponível em: www.legjur.com.br Acesso em: 12 jun. 2019.

BRASIL. Pacto Nacional pelo Enfrentamento à Violência contra as Mulheres. Brasília: Secretaria de Políticas para as Mulheres/Presidência da República, 2011.

BRASIL. Superior Tribunal de Justiça. Sexta Turma. Agravo Regimental em Agravo em Recurso Especial $n^{o}$ 1454781. Relator: Ministro Sebastião Reis Júnior, Julgamento: 17 dez. 2019, Publicação: 19 dez. 2019.

CASSOL, Paula D.; SILVA, Maria B. O da; DINARTE, Priscila V. "A vida mera das obscuras": sobre a vitimização e a criminalização da mulher. Revista Direito e Praxis, Rio de Janeiro, v. 9, n. ${ }^{\circ}$ 2, p. 810-831, Junho, 2018. Disponível em: $<$ www.scielo.br/scielo.php?script=sci_arttext\&pid=S2179-

89662018000200810\&lng=en\&nrm=iso> Acesso em: 29 mai. 2020.. $<$ https://doi.org/10.1590/2179-8966/2017/25503>. 
GOFFMAN, Erving. Estigma: notas sobre a manipulação da identidade deteriorada. Rio de Janeiro: LTC, 2008.

GOMES, Ana P. P. F. Como morre uma mulher? Configurações da violência letal contra mulheres em Pernambuco. Tese (doutorado). Universidade Federal de Pernambuco, Programa de Pós-Graduação em Sociologia, Recife-PE, 2014. Disponível em: <https://repositorio.ufpe.br/handle/123456789/13977.> Acesso em: 22 fev. 2020.

GUSMÃO , Carolina F., GUSMÃO, Tássia M. Violência de gênero e a lei maria da penha: aspectos históricos e a efetividade da lei no âmbito do direito do trabalho. Captura Críptica: direito, política, atualidade. Florianópolis, v. 6, n. 1, 2017. P. 141152.

$<$ http://ojs.sites.ufsc.br/index.php/capturacriptica/article/view/3070>. Acesso em: 22 fev. 2020 .

HIRATA, Helena. Gênero, classe e raça: Interseccionalidade e consubstancialidade das relações sociais. Tempo Social, Revista de Sociologia da USP, v. 26, nº. 1, junho, 2014. P. 61-73. Disponível em: <www.scielo.br/pdf/ts/v26n1/05.pdf.> Acesso em: 20/03/2020.

MENEGHEL, Stela N, PORTELLA, Ana P. Feminicídios: conceitos, tipos e cenários. Ciências e Saúde Coletiva, 2017, vol.22, n.9, pp.3077-3086. Disponível em: $<$ www.scielo.br/scielo.php?pid=S1413-

$81232017002903077 \&$ script=sci_abstract\&tlng=pt>. Acesso em: 22 mar.2020.

MENEGHEL, Stela. N.; HIRAKATA, Vânia N. Femicídios: homicídios femininos no Brasil. Revista de Saúde Pública. São Paulo, v. 45, n. 3, jun. 2011. p.564-574. Disponível em: <www.scielo.br/pdf/rsp/v45n3/1931.pdf>. Acesso em: 20 mar. 2020.

PASINATO, Wânia. Lei Maria da Penha: novas abordagens sobre velhas propostas. Onde avançamos? Civitas, Porto Alegre, v. 10, n. 2, p. 216-232, mai/ago. 2010. 
<www.tjse.jus.br/portaldamulher/arquivos/documentos/artigos/feminicidio.pdf>. Acesso em: 20 mar. 2020.

. Femicídios e as mortes de mulheres no Brasil. Cad. Pagu, n.37, p. 219- 246, 2011. Disponível em: <https://www.scielo.br/scielo.php?pid=S010483332011000200008\&script=sci_abstract\&tlng=pt> . Acesso em: 22 mar. 2020.

RESADOR , Alice H., RIOS, Roger R. Identidades de gênero e o debate étnico-racial no direito brasileiro Autodeclaração como técnica de proteção antidiscriminatória. Civitas, Porto Alegre, v. 18, n. 1, p. 10-25, jan.-abr. 2018. Disponível em: $<$ https://www.scielo.br/pdf/civitas/v18n1/1519-6089-civitas-18-01-0010.pdf $>$. Acesso em: 20 jan. 2020.

STAUDT, Kathleen. Lições da Primeira Onda de Pesquisa e Ativismo sobre o Feminicídio. Revista Brasileira de Segurança Pública, São Paulo, Ano 5, ed. 8 Fev/Mar, p.194-204, 2011. Disponível em: $<$ http://revista.forumseguranca.org.br/index.php/rbsp/article/view/91>. Acesso em: 23 abr. 2020.

VIEIRA. Pâmela R. L. GARCIA. MACIEL, Posenato, Ethel Leonor N. Isolamento social e o aumento da violência doméstica: o que isso nos revela? Revista Brasileira de Epidemiologia. Vol. 23. Rio de Janeiro: EPUB, 2020. Disponível em: $<$ https://www.scielo.br/scielo.php?pid=S1415-

790X2020000100201\&script=sci_arttext\&tlng=pt>. Acesso 10 jun. 2020.

WAISELFISZ, J. J. Mapa da Violência 2015: Homicídios de mulheres no Brasil. Distrito Federal: 2015.2 Disponível em: $<$ http://www.onumulheres.org.br/wpcontent/uploads/2016/04/MapaViolencia_2015_mulheres.pdf>. Acesso em 20 abr. 2020. 